Saudi Journal of Oral and Dental Research

Abbreviated Key Title: Saudi J Oral Dent Res

ISSN 2518-1300 (Print) |ISSN 2518-1297 (Online)

Scholars Middle East Publishers, Dubai, United Arab Emirates

Journal homepage: https://saudijournals.com/sjodr

Review Article

\title{
Surgical Guides in Implants: A Review
}

Dr. Shilpa Sunil Khanna ${ }^{1^{*}}$, Dr. Balaji Sugriv Munde ${ }^{2}$, Dr. Priyadarshani Madhukar Baisane ${ }^{3}$, Dr. Syed Shujaulla ${ }^{4}$, Dr. Syeda T Tabasum ${ }^{5}$, Dr. Mohammed Shammas ${ }^{6}$

${ }^{1}$ M.D.S, Department of Oral and Maxillofacial Surgery, Senior Lecturer, Sri Ramakrishna Dental College and Hospital, Coimbatore, Tamil Nadu, India ${ }^{2}$ MDS, Senior Lecturer, Department of Prosthodontics, Maharashtra Institute of Dental Sciences \& Research Dental College, Latur, Maharashtra, India ${ }^{3}$ Sr. Lecturer, Department of Prosthodontics, A.C.P.M. Dental College Dhule, Maharashtra, India

${ }^{4}$ Assistant Professor, Department of Prosthetic Dental Sciences, College of Dentistry, Qassim University, Buraidah, K.S.A

${ }^{5}$ Associate Professor, Department of Periodontology, College of Dentistry, Qassim University, Buraidah, KSA

${ }^{6}$ Associate Professor, Division of Prosthodontics, Department of Oral and Maxillofacial Rehabilitation, Ibn Sina National College for Medical Studies, Jeddah, K.S.A

DOI: $10.36348 /$ sjodr.2020.v05i09.001

| Received: 22.08.2020 | Accepted: 30.08.2020 | Published: 03.09.2020

*Corresponding author: Dr. Shilpa Sunil Khanna

\section{Abstract}

Replacement of missing teeth with dental implants is has greater curve In recent days.as the importance of the treatment increases the researches among this procedure also increased.in this way so may new methods also invented to improve the treatment success. Placement of dental implants with the help of the dental implants is a successful criteria in present days.so the main aim of this review articles is to describe the various implant surgical stents and to describe the considerations to use the implant surgical guides

Keywords: Implant, guide, scan.

Copyright @ 2020: This is an open-access article distributed under the terms of the Creative Commons Attribution license which permits unrestricted use, distribution, and reproduction in any medium for non-commercial use (NonCommercial, or CC-BY-NC) provided the original author and source are credited.

\section{INTRODUCTION}

The most dominated treatment criteria for replacement of missing tooth is dental implants. previously failures were more common in dental implants it might be because of failure in implementation if the treatment plan during the procedure. To avoid errors during placement and to proper implementation of the treatment plant surgical templates were introduced. Surgical guides (stents) are templates that transfer information regarding tooth position to the dentist prior to implant placement. previously dental implant position and placement mainly depends on residual bone availability only [1]. Because of this after placement of implant planning of prosthesis is very difficult. To avoid these difficulties prosthetic driven implantology was introduced. This prosthetic driven implantolgy includes surgical guides or surgical templates. Surgical guide templates not only assist in diagnosis and treatment planning but also facilitate proper positioning and angulation of the implants in the bone [2]. Moreover, restoration driven implant placement accomplished with a surgical guide template can decrease clinical and laboratory complications. Hence, increasing demand for dental implants has resulted in the development of newer and advanced techniques for the fabrication of these templates [3].
Definition: According to GPT9 surgical guide can be define as:

1. Any device used as a guide for surgically shaping the alveolar process or positioning of gingival tissues;

2. A guide used to assist in proper surgical placement and angulation of dental implants.

3. A guide used to assist in establishing the desired occlusion during orthognathic or grafting surgery [4].

\section{Ideal Requirements}

It should be rigid in correct position buccolingually mesio distally, apico coronally

\section{Extensions of the Surgical Guides}

If the arch treated has remaining teeth, the template should fit over and/or around enough teeth to stabilize and position the guide stent. When no remaining teeth are present, the template should extend onto unreflected soft tissue regions, that is, the palate and tuberosities in the maxilla, or the retromolar pads in the mandible. In this way, the guide template may be used after the soft tissue has been reflected from the implant site, and during preparation for the implant osteotomy $[5,6]$. 


\section{Implant Angulation}

The ideal angulation for implant insertion should be visualized during surgery and requires, at least, two reference points for each implant. For that purpose, the surgical guide must be elevated above the edentulous site. The distance between the occlusal surface of the abutment crown and the crest of the ridge represents $8 \mathrm{~mm}$ or more. As a result, these two points of reference correspond to the path of ideal implant insertion. The ideal angulation is perpendicular to the occlusal plane and parallel to the most anterior abutment joined to the implant [7].

\section{Gingival Contouring}

The surgical template should relate the ideal gingival contour position. Lost bone and gingival width may be replaced during implant insertion by an onlay graft of dense hydroxyapatite and demineralized freezedried bone. The amount of augmentation required to support the tissue can be determined by the surgical template

\section{Uses}

- To Guide the osteotomy drills at correct position, angulation and depth.

- To Guide the implant fixtures at correct position, angulation and depth.

- Guidance of amount of bone reduction or bone harvesting if necessary (both soft tissue and hard tissue harvesting) [3].

\section{Advantages}

Decreases manual errors associated with free hand implant placement - Minimally invasive procedures, postoperative surgical problems are minimized providing psychological benefit to both patient and clinician - Precision - Implants are prosthetically driven components; any deviation can lead to abrupt results in functioning. With surgical guides, implant placement has become more accurate Safety: Safety is one of the important factor when placing implants in critical areas of the mouth. Even the small error can lead to severe complications. With the help of surgical guides, such errors can be prevented. Vital structure can be protected with surgical guides • Predictability; Predicability is more with surgical guides. Aesthetics - because of computer aided treatment planning and exact and easy implementation of treatment planning leads to good aesthetics results. • Hygiene - Maintenance of proper oral health is ensured because of correct implant placement - For best survival, implant supported prosthesis should be placed in preplanned positions. Guides can help such quality placements of implants - Reduction of implant surgery time - Ease in fabrication: because of computer aided designs fabrication is easy• Special surgical guide types, such as bone reduction guides are available that can enable graft harvesting - Guide itself can act as a temporary prosthesis for fully edentulous cases Accessabillity:Increased visibility of the surgical site and easy access for flap exposure $\cdot$ because of less failures and exacts implementation of treatment planning patient visits can be reduced $[8,9]$.

\section{Disadvantages}

Surgical guides do not allows the predetermined position of the dental implant if any modifications requires at the time of surgery. Any tissue changes like (soft tissue changes like swellings and hard tissue changes like loss of abutment teeth) may alter the fit of the stent which leads to the failure of the dental implant placement. Guide dislocation at the time surgical procedure. Drill lodgement in stents - Guide dislocation also occurs when drilling is intended to penetrate hard bone, producing torsional forces on the sleeves, thus lifting off the guide - Start-up cost associated with software purchasing $\bullet$ Greater learning curves [9].

\section{Classification Of The Surgical Guides [10-12]:}

Based on the area of operation

\section{Guides for partially edentulous sites \\ Tooth supported \\ Bone supported}

In case of short span partially edentulous arches tooth supported surgical guides can be used, incase of long span partially edentulous arches tooth and bone supported implant surgical guides can be used.

Guides for completely edentulous site: Mucosa or bone supported.

Based on the support: The surgical guides derives support from Teeth, Bone and Mucosa.

Rules for planning usage of different types of surgical guides

Tooth supported guides: Minimum three stable teeth should be present to support the guide during surgery - Mucosa supported guides - It is used in fully edentulous sites. Advantage-less or no tissue reflection is required, so less postoperative discomfort. Will require scan prosthesis and surgical guides during surgery - Bone supported guides - They are used in partially edentulous sites and completely edentulous sites. When used in partially edentulous sites, it should possess at least $3 \mathrm{~cm}$ of supporting bone or 3 teeth would need replacement. Bone guides are especially used when edentulous sites possess thin bone. Raised flap should provide a good view to implant sites and insertion of guides.

Based on the accessibility: open sleeve \& closed sleeve, accessibility is high with closed sleeve implant surgical guides. 


\section{Based on Utility}

\section{Pilot Guides}

This surgical guides allows only pilot driils so that only Angulation control is achieved. Depth control is to be obtained manually by assessing markings on drills. After pilot drilling the surgical guide has to be removed, and osteotomy site is expanded in the absence of surgical guide $•$

\section{Complete Drill Guides}

It different drill keys or sleeves. Different sleeves for different diameters of drills, which are changed concomitantly as osteotomy is widened. Angulation as well size of osteotomy is controlled by guide; depth is controlled manually •

\section{Safe Guides/Easy Guides}

Uses drill key or sleeves as above with additional implant stopper that controls the depth of drilling. Allows both osteotomy and implant placement.

\section{Based on Material}

Self/light cure acrylic resin, metal reinforced acrylic templates; vacuum formed polymers, milling, CAD-CAM prosthesis, stereo lithographic models. The surgical accuracy of manually processed resin and vacuum formed guides is less in comparison to the latter mentioned milling, CAD-CAM prosthesis or stereo lithographic models.

\section{Classification of Design Concepts for Fabrication of Surgical Guide [13-17]}

Based on the amount of surgical restriction offered by the surgical guide templates:

\section{Non Limiting Design}

Blustein et al., and Engelman et al., described a technique in which a guide pin hole was drilled through a clear vacuum-formed matrix. This hole indicated the optimal position of the dental implant. However, the angulation was determined by the use of adjacent and opposing teeth

\section{Partially Limiting Design}

In such designs, the first drill used for the osteotomy is directed using the surgical guide, and the remaining osteotomy and implant placement is then finished in freehand by the surgeon. Techniques based on this design concept involve fabrication of a radiographic template, which is then converted into a surgical guide template following radiographic evaluation. This technique failed to completely restrict the angulation of the surgical drills.

\section{Completely Limiting Design}

This design restrics all the instruments used in surical procedure during imlant placement. Drill stops limits the depth of the preparation.As the surgical guides become more restrictive, less of the decisionmaking and subsequent surgical execution is done intraoperatively [18].

This includes 2 popular designs:

- Cast-based guided surgical guide

- Computer-assisted design and manufacturing (CAD/CAM) based surgical guide.

\section{Cast Based Guided Surgical Guide}

Combination of an analogue technique done along with bone sounding and the use of periapical radiographs in a conventional flapless guided implant surgery. The periapical radiograph is modified using digital software to help in transposition of root structure onto the cast. The cast is then sectioned at the proposed implant site, and bone-sounding measurements are transferred to help in orientation of the drill bit to perform a cast osteotomy.

A laboratory analog is placed in the site, and a guide sleeve consistent with the implant width is modified using wires that are used to create a framework around the teeth. Vinyl polysiloxane occlusal registration material is used to form the superstructure

\section{CAD/CAM Based Implant Surgical Guides}

The procedure for fabrication of $\mathrm{CAD} / \mathrm{CAM}$ based surgical guides can be divided into the following steps:

- Fabrication of the radiographic template,

- The computerized tomography scan,

- Implant planning using interactive implant surgical planning software,

- Fabrication of the stereolithographic drill guide.

\section{Fabrication of the Radiographic Template [18-21]}

The radiographic template must be an exact replica of the desired prosthetic end result, as it allows the clinician to visualize the location of planned implants from an esthetic and biomechanical standpoint.

This is followed by fabrication of an interocclusal index, to allow reproducible placement of the scan template intraorally.

\begin{tabular}{|l|l|}
\hline First Scan & Second Scan \\
\hline $\begin{array}{l}\text { he patient is scanned wearing the radiographic scan template } \\
\text { and radiographic index (interocclusal index) }\end{array}$ & $\begin{array}{l}\text { The second scan is performed without the } \\
\text { index. }\end{array}$ \\
\hline $\begin{array}{l}\text { The first scan is used to visualize the bony architecture and } \\
\text { anatomy of the site of interest }\end{array}$ & $\begin{array}{l}\text { second scan is performed to visualize the } \\
\text { nonradiopaque radiographic guide }\end{array}$ \\
\hline
\end{tabular}


The 2 resulting sets of 2D CT data (Digital Imaging and Communication in Medicine [DICOM files]) are then superimposed over each other according to the radiographic markers and are further converted into a file format compatible with the $3 \mathrm{D}$ planning program. Resulting from this fusion is an exact representation of the patient's bone structure and scanning denture in $3 \mathrm{D}$ space. At this point, the virtual surgical procedure can be performed. A 3D implant planning software allows for simultaneous observation of both the arches and the radiographic scan template in 3 spatial planes and helps to virtually plan the location, angle, depth, and diameter of the virtual implants. It produces an axial image, a panoramic image, and a series of cross-sectional images on the screen at the same time. Various implant planning Software products are available commercially, Namely, simplant, surgicase (materialise dental Inc, leuven, belgium), procera (nobel biocare,Go" teborg, sweden), implantmaster (i-dent imaging Ltd, hod hasharon, israel), codiagnostix (IVS Solutions AG, chemnitz, germany), and easy guide(Keystone dental, burlington, MA ). Once the computer planning is accomplished, this plan is saved as a ".sim" file and sent to the processing center for fabrication of the surgical guide, using stereolithography. Stereolithography is a computerguided, laser-dependent, rapid prototyping polymerizationn process that can duplicate the exact shape of the patient's skeletal anatomic landmarks in a sequential layer of a special polymer to produce a special 3D transparent resin model, which fits intimately with the hard and/or soft tissue surface. Once hardened, the polymeric prototype contains spaces for stainless steel or titanium drill-guiding tubes. These tubes precisely guide the osteotomy drills, precluding the need for the pilot drills.

\section{Advantages of Completely Limiting Design}

The virtual 3-dimensional (3D) views of the bony morphology allow the surgeon to visualize the surgical bone site prior to implant placement; risks such as inadequate osseous support or compromise of important anatomic structures are avoided. Incorporation of prosthetic planning using a scanographic template allows the treatment to be optimized from a prosthodontics and biomechanical point of view. This technique promotes flapless surgeries, allows presurgical construction of the master cast and provisional restorations, and facilitates immediate loading [22].

\section{Disadvantages of the Completely Limiting Design}

Special training for familiarity with the entire system and special equipment is necessary. Considerable number of technique-related complications were observed. The various complications recorded were related to inaccurate planning, radiographic stent error, intrinsic errors during scanning, software planning, the rapid prototyping of the guide stent, and the transfer of information for the prosthetics. However, if the clinician recognizes these sources of inaccuracy, efforts can be made to minimize the error and optimize patient treatment [23].

\section{Implant Surgical Guide Kit}

Surgical guide kit contains drill handle, guide tubes, c handle, template fixation pins, retentive anchor driver, stop key for guided implants, mucosal punch, Tsleeve.

\section{Selection of Retentive Anchor Pins}

Mainly depends on type of the surgical guide, implant number, position of edentulous site, presence of any anatomical limitations (maxillary sinus, mandibular nerve), and length of fixation screws. Ideally the fixation screws should be positioned vertically because vertical position stabilizes the guide the most and also the have the added advantage of easier accessibility for placement [24].

\section{Considerations for Selection Retentive Anchor Pins For Mucosa Supported Guides}

At least three in number. Two anchors positioned at distal ends, and one anchor positioned in the center of edentulous arch. The distal areas or posterior areas usually contain important structures such as maxillary sinus, mandibular nerves. In such conditions, we have to take these structures into consideration and plan more distally as possible. While using a mucosa supported guides, the undercuts are relieved in the labial region where the fixation anchors are attached. Screwing in these areas can lift the guide away from the mucosal tissues. Latter can be prevented by holding the guide initially till at least positioning one screw in position [25].

\section{For Tooth Supported Guides}

If edentulous site is bound by teeth bilaterally, then fixation anchor is positioned in the middle of the edentulous site. If distal edentulous site: Fixation anchors are positioned as distally as possible in the arch, not necessarily adjacent to distal edentulous site.

\section{For Bone Supported Guides}

Two fixation anchors are enough to rigidly fix the guide to the bone. One on the right side and other to the left. In the undercut area, tilting off or lift off of the guide can occur on tightening the screw. Latter is prevented by holding the guide while the second anchor is tightened. It is not a rule that the whole of the guide should contact bony tissue.

\section{Steps in Usage of Implant Surgical Guide}

Step 1: Diagnosis and treatment planning. Step 2: Virtual treatment planning of dental implant and prosthesis in CT software. Step 3: proper selection of particular implant system and components. Step 4: Planning for the surgical guide compatible with particular implant system. If more than 3 teeth tooth borne surgical guide has to be selected, if less than 3 
teeth mucosa or bone borne surgical guide has to be selected. Step 5: Selection of anchors depending on the site, implant number, angulation, anatomical limitation Step 6: Surgical guide fabrication (online ordering is possible with most soft wares) Step 7: Disinfection of received surgical guides followed by evaluation of guides. Teeth supported surgical guides must be evaluated on cast and in patients mouth. Mucosa supported surgical guides must be evaluated on cast and patients mouth, for a mucosa supported guide, it is recommended to make a surgical index to stabilize the guide during fixation. For bone supporte devaluate on digital bone model. Step 8: Verification of specific surgical drills and drill keys. Step 9: Stabilization of guides in patient's mouth using anchor pins followed by verification of the guide stability. Step 9: Drill sequence. Step 10: Fixture installation (possible with safe guides) [26-28].

\section{CONCLUSION}

Dental implants are the better treatment of choice in recent days for replacement of missing teeth. For success of dental implants proper execution of treatment plan is important. Various studies have shown that dental implant placement with the help of surgical guides is a successful criteria than conventional dental implant placement.

\section{REFERENCES}

1. Abd El Salam El Askary. (2003). Reconstructive Aesthetic Implant Surgery. Vol. 2. Ames, Iowa: Blackwell Munksgaard. 33-34

2. Akça, K., Iplikçioglu, H., \& Cehreli, M. C. (2002). A surgical guide for accurate mesiodistal paralleling of implants in the posterior edentulous mandible. J Prosthet Dent. 87:233-235.

3. Orentlicher, G., \& Abboud, M. (2011). Guided surgery for implant therapy. Oral Maxillofac Surg Clin North Am. 23:239-56.

4. Ferro, K. J., Morgano, S. M., Driscoll, C. F., Freilich, M. A., Guckes, A. D., \& Knoernschild, K. L. (2017). The glossary of prosthodontic terms. $J$ Prosthet Dent, 117(5S), e1-e105.

5. Drill guides for every case scenario: Surgi Guide Cookbook. Available from: http://www.materialisedental.com/materialise/vie w/en/2395185.SurgiGuide+dental+drill+guide+Co okbo ok.html. [Last cited on 2013 Aug 25].

6. Abd El Salam El Askary. (2003). Reconstructive Aesthetic Implant Surgery. Vol. 2. Ames, Iowa: Blackwell Munksgaard. 33-34.

7. Fortin, T., Champleboux, G., Lormée, J., \& Coudert, J. L. (2000). Precise dental implant placement in bone using surgical guides inconjunction with medical imaging techniques. $J$ Oral Implantol. 26:300- 303.

8. Martins, R. J., \& Lederman, H. M. (2013). Virtual planning and construction of prototyped surgical guide in implant surgery with maxillary sinus bone graft. Acta Cir Bras. 28:683-690.

9. Huh, Y. J., Choi, B. R., Huh, K. H., Yi, W. J., Heo, M. S., Lee, S. S., \& Choi, S. C. (2012). In-vitro study on the accuracy of a simple-design CTguided stent for dental implants. Imaging science in dentistry, 42(3), 139-146.

10. Zitzmann, N. U., \& Marinello, C. P. (1999). Treatment plan for restoring the edentulous maxilla with implant- ${ }^{-}$supported restorations: Removable overdenture versus fixed partial denture design. J Prosthet Dent. 82:188- 96.

11. Lal, K., White, G. S., Morea, D. N., \& Wright, R. F. (2006). Use of stereolithographic templates for surgical and prosthodontic implant planningand placement. Part II. A clinical report. J Prosthodont. 15:117- 22.

12. Moslehifard, E., \& Nokar, S. (2012). Designing a custom made gauge device for application in the access hole correction in the dental implant surgical guide. J Indian Prosthodont Soc. 12:123129.

13. Implants retrieved from patients with and without osteoporosis. Int $J$ Oral Maxillofac Surg. 2008;37:321-327.

14. Slagter, K. W., Raghoebar, G. M., Vissink, A. (2008). Osteoporosis and edentulous jaws. Int J Prosthodont. 21:19-26.

15. Kido, H., Schulz, E. E., Kakura, K., Yamamoto, K., Morinaga, K., \& Matsuura, M. (2011). Human mandibular trabecular bone density correlation with mechanical strength: implications for implant dentistry. Implant Dentistry, 20(4), 323-326.

16. Amorim, M. A., Takayama, L., Jorgetti, V., \& Pereira, R. M. (2007). Comparative study of axial and femoral bone mineral density and parameters of mandibular bone quality in patients receiving dental implants. Osteoporos Int. 18:703-709.

17. Friberg, B., Ekestubbe, A., Mellstro“m, D., \& Sennerby, L. (2001). Bra ${ }^{\circ}$ emark implants and osteoporosis: a clinical exploratory study. Clin Implant Dent Relat Res. 3:50-56.

18. Scully, C., Madrid, C., \& Bagan, J. (2006). Dental endosseous implants in patientson bisphosphonate therapy. Implant Dent. 3:212-218.

19. Madrid, C., \& Sanz, M. (2009). What impact do systemically administrated bisphosphonates have on oral implant therapy? A systematic review. Clin Oral Implants Res. (suppl 4):87-95.

20. Pazianas, M., Miller, P., Blumentals, W. A., Bernal, M., \& Kothawala, P. (2007). A review of the literature on osteonecrosis of the jaw in patients with osteoporosis treated with oral bisphosphonates: prevalence, risk factors, and clinical characteristics. Clin Ther. 29:1548-1558.

21. Gómez, F. R., Martínez, G. M., \& Olmos, M. J. (2008). Osteochemonecrosis of the jaws due to bisphosphonate treatments. Update. Medicina oral, patologia oral y cirugia bucal, 13(5), E318-324. 
22. Woo, S. B., Hellstein, J. W., \& Kalmar, J. R. (2006). Narrative [corrected] review: bisphosphonates and osteonecrosis of the jaws. Ann Intern Med. 144:753-761.

23. Fugazzotto, P. A., Lightfoot, W. S., Jaffin, R., \& Kumar, A. (2007). Implant placement with or without simultaneous tooth extraction in patients taking oral bisphosphonates: postoperative healing, early follow- up, and the incidence of complications in two private practices. Journal of periodontology, 78(9), 1664-1669.

24. Marx, R. E. (2007). Oral and Intravenous Bisphosphonate-Induced Osteonecrosis of the Jaws: History, Etiology, Prevention, and Treatment. 1st ed. Hanover Park, Ill: Quintessence.
25. Starck, W. J., \& Epker, B. N. (1995). Failure of osseointegrated dental implants after diphosphonate therapy for osteoporosis: a case report. Int J Oral Maxillofac Implants. 10:74-78.

26. Jeffcoat, M. K. (2006). Safety of oral bisphosphonates: controlled studies on alveolar bone. Int J Oral Maxillofac Implants. 21:349-353.

27. Wang, H. L., Weber, D., \& McCauley, L. K. (2007). Effect of long-term oral bisphosphonates on implant wound healing: literature review and a casereport. J Periodontol. 78:584-594.

28. Yuan, K., Chen, K. C., Chan, Y. J., Tsai, C. C., Chen, H. H., \& Shih, C. C. (2012). Dental implant failure associated with bacterial infection and long-term bisphosphonate usage: a case report. Implant dentistry, 21(1), 3-7. 